This is the accepted manuscript of the article, which has been published in Vaccine. 2019, 37(23), 3078-3087.

https://doi.org/10.1016/j.vaccine.2019.04.058

\title{
Vaccination coverage and factors associated with routine childhood vaccination uptake in rural Vellore, southern India,
}

\section{7}

Mark Rohit Francis a , J.Pekka Nuorti ${ }^{a}$ b , Rajeev Zachariah Kompithra ${ }^{c}$, Heidi Larson ${ }^{\text {, }}$ Vinohar Balraj e, Gagandeep Kang ${ }^{f}$, Venkata Raghava Mohan ${ }^{9}$, *

a Health Sciences Unit, Faculty of Social Sciences, Tampere University, Finland

${ }^{\mathrm{b}}$ Infectious Diseases and Vaccines, Department of Health Protection, National Institute for Health and Welfare, Helsinki, Finland

${ }^{\mathrm{c}}$ Well Baby Immunization Clinic, Department of Pediatrics Unit - I, Christian Medical College, Vellore, Tamil Nadu, India

${ }^{\mathrm{d}}$ Department of Infectious Disease Epidemiology, London School of Hygiene and Tropical Medicine, London, United Kingdom

e Society for Applied Studies, Vellore, Tamil Nadu, India

${ }^{f}$ Division of Gastrointestinal Sciences, Christian Medical College, Vellore, Tamil Nadu, India

${ }^{g}$ Department of Community Health, Christian Medical College, Vellore, Tamil Nadu, India

Abstract word count: 287

Main-text word count: 3,800

* Corresponding author at: Department of Community Health, Christian Medical College, Vellore, Tamil Nadu, India; Email: venkat@cmcvellore.ac.in 


\section{Abstract}

Background: Vellore district in southern India was selected for intensified immunization efforts through India's Mission Indradhanush campaign based on $74 \%$ coverage in the National Family Health Survey in 2015. As rural households rely almost entirely on the Universal Immunization Program (UIP), we assessed routine immunization coverage and factors associated with vaccination status of children in rural Vellore.

Methods: We conducted a cross-sectional household survey among parents or primary caretakers of children aged 12-23 months during August-September 2017 using twostage, EPI cluster sampling. We verified vaccination histories from vaccination cards and collected data on sociodemographic and non-socio-demographic characteristics by using mobile data capture. Associations with vaccination status were examined with univariate and multivariate logistic regression models.

Results: A total of 643 children were included. Coverage of BCG, third dose pentavalent/DPT, measles/MR vaccines and full vaccination (BCG, three doses of polio and pentavalent/DPT and measles/MR vaccines) among children with vaccination cards ( $\mathrm{n}$ = 606) was 94\%, 96\%, 93\% and 84\%, respectively. Of children with vaccination cards, $70.8 \%$ had received all recommended doses according to the UIP schedule. No sociodemographic differences were identified, but parents' familiarity with the schedule (Adjusted Prevalence Odds Ratio (aPOR): $2.06,95 \% \mathrm{Cl}=1.26-3.38$ ) and receiving information on recommended vaccinations during antenatal visits (aPOR: $2.16,95 \% \mathrm{Cl}=$ $1.13-4.12$ ) were significantly associated with full vaccination status of the children.

Conclusions: We found higher UIP antigen coverage and proportion of fully vaccinated children than previously reported from rural Vellore. However, adherence to the recommended schedule was still not optimal. Our study highlights the potential of improving parental awareness of vaccination schedule and targeting health education 
interventions at pregnant women during antenatal visits to sustain and improve routine immunization coverage.

Keywords: Universal immunization program, Mission Indradhanush, EPI cluster survey, routine immunization coverage, rural Vellore

Abbreviations: MI, Mission Indradhanush; NFHS, National Family Health Survey; EPI, Expanded Program on Immunization; UIP, Universal Immunization Program; BCG, Bacillus Calmette-Guerin; DPT, Diphtheria-Pertussis-Tetanus; OPV, Oral Polio Vaccine; IPV, Inactivated Polio Vaccine; MR, Measles-Rubella vaccine; PCV, Pneumococcal conjugate vaccine; PSU, Primary Sampling Unit. 


\section{Introduction}

India's Universal Immunization Program (UIP) is one of the largest public health initiatives in the world in terms of the quantity of vaccines delivered, number of beneficiaries reached and the geographic diversity of regions covered [1]. The UIP provides free vaccines against tuberculosis (BCG), poliomyelitis (OPV and IPV), diphtheria, pertussis, tetanus, $H$. influenzae type b, hepatitis B (pentavalent), measles, Japanese Encephalitis (in endemic districts) and recently Rubella (MR), rotavirus diarrhea and pneumococcal diseases (PCV) in some Indian states [2,3]. Perhaps the greatest achievement of the Indian UIP is the eradication of polio, with India certified "polio-free" in 2014 [4]. Despite nearly three decades of the UIP, an estimated 500,000 children still die annually of vaccine preventable diseases and only $62 \%$ of children receive the full schedule of UIP vaccines during their first year of life according to a report by the National Family and Health Survey (NFHS-4) conducted during 2015-16 [5,6]. The suboptimal coverage of UIP vaccines suggests that nearly 10 million of the 26 million children born every year in India might be partiallyvaccinated or completely unvaccinated $[7,8]$.

The Indian government launched the Mission Indradhanush (MI) campaign in 2015 aiming to increase the coverage of recommended UIP vaccines during the first year of life to $90 \%$ by $2020[1,9]$.The campaign is conducted in four phases and targets districts with the lowest immunization coverage across the country $[1,9]$. Strategies to improve routine immunization coverage include special immunization sessions, enhanced community engagement and mobilization, intensive training of health workers and increased accountability at all levels of program implementation [9]. Recent administrative reports suggest that full immunization coverage among children aged 12-23 months has increased by $5-7 \%$ after the first two phases of Mission Indradhanush [10]. However, aggregated coverage estimates often conceal important regional disparities [11]. For example, NFHS- 
4 reports full immunization coverage above $80 \%$ for states such as Kerala, Punjab, Goa and Sikkim, whereas states like Arunachal Pradesh and Assam have a coverage of 38\% and $47 \%$ respectively [6]. Even Tamil Nadu, the only Indian state with conditional cash transfer to economically-disadvantaged mothers whose children have completed the primary vaccination series (until the third dose of pentavalent vaccine) has significant district-level differences in immunization coverage $[6,12,13]$.

The district of Vellore in Tamil Nadu was selected as one of 201 "high-focus" districts for intensified routine immunization as part of the MI campaign in 2015 [14]. The NFHS-4, however, reported full immunization coverage of $74 \%$ for Vellore, with important urbanrural difference (78\% vs. $69 \%$ respectively) [6]. Since rural households are almost entirely dependent on immunization services provided by the UIP, it is important to investigate the reasons for the suboptimal coverage and identify potential disparities in the uptake of routine childhood vaccination that may be addressed by targeted interventions [15]. The objective of our study was to assess routine immunization coverage and the factors associated with the vaccination status of children aged 12-23 months in rural Vellore. As a secondary objective, we also describe and evaluate the factors associated with adherence to the UIP schedule, which are generally not reported by administrative and national health surveys in India.

\section{Methods}

\section{Study setting}

The study was conducted in Thimiri, a rural administrative block comprising 67 villages in Vellore district in Tamil Nadu, India. Thimiri is one of the larger blocks of the Vellore district with a population of 105,691 , with 11,242 children aged six years or younger and literacy of approximately 65\% (2011 census). Thimiri was selected as it is easily accessible by road and expected to be representative of the routine immunization services available to 
the other blocks of the district. Routine immunization is provided in primary health centers, childcare centers (Anganwadis) or the government district hospital at no cost to parents. A Measles-Rubella (MR) vaccination campaign was held during February-March 2017 to provide a single dose of the vaccine to all children aged 9 months to 15 years before formal introduction into the UIP schedule, replacing the monovalent measles vaccine. Numerous private clinics and hospitals around Thimiri and other parts of Vellore also provide UIP and non-UIP vaccinations for a fee, and generally use the Indian Academy of Pediatrician (IAP) immunization schedule [16].

\section{Survey procedure and sample size}

A household survey of children aged 12-23 months (henceforth called "eligible children") was conducted during August and September 2017, using two-stage cluster sampling based on the Expanded Program on Immunization (EPI) coverage survey methodology [17]. First, 30 clusters were selected with probability proportional to size (PPS), with a cluster defined as a village or a group of congruent villages with a population of $\geq 2000$ individuals (or $400-500$ households). At the second stage, from the geographic center of each cluster, a direction for survey and the starting household were selected randomly using EPI guidelines [18]. The next nearest households were based on proximity to the prior household; sampling continued until the required number of children were surveyed in each cluster or until the last household with an eligible child in a given cluster was reached. If multiple children in the eligible age group were present in a household, only the youngest child was included.

The proportion of fully vaccinated children (children who received one dose of BCG and measles and three doses each of DPT \& OPV vaccines) according to the NFHS-4 for rural Vellore was $70 \%$ [19]. Using this estimate with an absolute precision of $\pm 5 \%$, anticipated design effect (deff) of 2 and inflating the effective sample size by $15 \%$ for potential non- 
response during the surveys, a total sample of 750 children aged $12-23$ months or 30 clusters of 25 children each was planned.

\section{Data collection \& management}

We used a structured, interviewer-administered questionnaire to collect information from parents or primary caretakers of eligible children from whom written informed consent was obtained. A primary caretaker had to be a relative involved in caring for the child and knowledgeable of their immunization history. The questionnaire was translated to Tamil and programmed using the "KoBo Toolbox", an open-source application for mobile data collection [20]. Both the translated paper and electronic versions of the questionnaire were pre-tested among parents of children aged 12-23 months in a non-study village. Range checks, skip patterns and pictures of children's vaccination cards were programmed into the interface to minimize data-entry errors. All the field staff had a three-day training session prior to survey commencement. $10 \%$ validation was independently done for randomly selected children. The study protocol received ethical clearance from the Institutional Review Board (IRB) of the Christian Medical College, Vellore (IRB no. 10691, dated 21.06.2017).

\section{Study variables}

The independent variables included socio-demographic characteristics such as parent age, education and occupation and household type, number of members, caste and religion and child characteristics like age at survey, birth order and places of birth and vaccination. Non-socio-demographic characteristics of the parents were outlined using the "5A's taxonomy for determinants of vaccine uptake" [21]. Information on issues of Access - mode of travel to the most frequented vaccination center, Affordability - timing of immunization services (a proxy for opportunity costs such as lost earnings or time), 
$\underline{\text { Awareness }}$ - familiarity with UIP schedule for children and the recently introduced MR

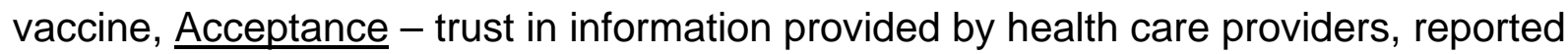
hesitancy about childhood vaccines and Activation - receipt of monetary incentive for completion of the pentavalent/DPT series, health-worker home visits and provision of information on the UIP schedule during antenatal visits was collected.

Data on routine childhood vaccinations administered during the first year of life were collected from the vaccination cards of eligible children (including doses and dates of vaccination) as well as parental report. If a vaccination card was not available, data were based on parental recall. Children without recorded dates for vaccination were assumed to have missed those doses and were asked for reasons for the missed doses [22,23]. The categorization of the primary and secondary outcomes are found in Table 1.

\section{Statistical Analysis}

Data were entered real-time on the KoBo Toolbox interface using Android ${ }^{\mathrm{TM}}$ devices. Data were uploaded to the KoBo server and downloaded for cleaning. Data cleaning included reviewing the completeness and validity of the variables collected and verification of the dates of birth and vaccination using the pictures of children's vaccination cards. Data were managed and analyzed using STATA (version 14, StataCorp LP, College Station, TX, USA).

The analyses accounted for the cluster sampling design using a cluster identifier as the primary sampling unit for survey specification in the "svy" package of STATA. Proportions of children aged 12-23 months receiving each of the recommended UIP doses and 95\% confidence intervals ( $\mathrm{Cls}$ ) were calculated using information based on 1 ) vaccination cards or parental recall and 2) vaccination cards alone. We also calculated the sensitivity and specificity of parental recall and vaccination card information to categorize children's 
vaccination status using the "diagt" package for STATA. The age of children at receipt of individual UIP doses was calculated by subtracting their birthdate from the dates of vaccination. All independent variables were analyzed categorically (see supplemental material). Univariate analysis to examine associations between the socio-demographic and non-socio-demographic variables with vaccination status used logistic regression. All independent variables with a significant univariate association at the $p \leq 0.20$ level were included in the multivariate regression models. The univariate and multivariate analyses were restricted to children with vaccination cards, however supplementary analyses were performed for all the surveyed children, i.e. irrespective of the source of vaccination history. Associations between the independent variables and full and schedule-appropriate vaccination status of children are presented as crude and adjusted Prevalence Odds Ratios (aPORs) with 95\% Cls derived from design-adjusted standard errors. As sensitivity analysis, we examined the factors associated with full and schedule-appropriate vaccination status after restriction to children exclusively vaccinated at public health facilities.

\section{Results}

\section{Participant characteristics}

A total of 643 children aged 12-23 months were included (one family declined to participate; survey response proportion $=99.8 \%$ ) in the survey. Mean $(S D)$ age of children was 18.2 (3.6) months, $52.6 \%$ were boys and $42.8 \%$ were firstborn. Of the children, $92.1 \%$ lived in cemented houses and $623(96.9 \%)$ belonged to Hindu families. Most children (94.2\%) received vaccination at public facilities. The characteristics of children and parents are presented in Tables 2 and 3, respectively.

\section{Vaccination coverage and adherence to the UIP schedule}


The coverage of important UIP doses and children's vaccination status are presented in Table 4. Of the children included, 606 (94.3\%) had a vaccination card and the rest reportedly had a vaccination card that could not be produced at the time of survey. There were no significant differences in the socio-demographic characteristics of children with and without vaccination cards (Supplemental Table 1). Vaccination coverage using information from vaccination cards or parental recall $(n=643)$ was $100 \%$ for BCG, and $99.2 \%$ and $98.1 \%$ for the third dose of pentavalent/DPT and measles/MR vaccination. The coverage of BCG, third dose of pentavalent/DPT and measles/MR vaccine among children with a vaccination card $(n=606)$ was $94.4 \%, 95.7 \%, 92.9 \%$ respectively. Coverage of the pentavalent/DPT and OPV doses was similar as these doses were mainly (>98\%) coadministered.

The proportion of fully vaccinated children was $96.4 \%$ and $84 \%$ for information based on parental recall or vaccination cards and vaccination cards alone, respectively. The sensitivity and specificity of parental recall to classify children's vaccination status using vaccination card information as the gold standard for children with a card $(n=606)$ was $95 \%$ and $21 \%$ respectively (Supplemental Table 2). Among the children with a vaccination card, $97(16 \%)$ were undervaccinated and only one of these children was completely unvaccinated. A majority $(72.2 \%, n=70)$ of the undervaccinated children missed 1 - 2 recommended UIP doses (Supplemental Table 3). The most frequently missed doses were measles/MR (22.4\% of all missed doses), BCG (17.7\%) and third dose of OPV or pentavalent/DPT vaccination ( $14.1 \%$ \& $13.6 \%$ respectively).

Of the 606 children with a vaccination card, $429(70.8 \%)$ had received all the recommended doses at the prescribed age and interval according to the UIP schedule, 80 $(13.2 \%)$ received all the recommended doses but at least one dose was not given according to schedule and 97 (16\%) missed one or more recommended doses. Failure to 
adhere to the UIP schedule among the 80 children who had received all the recommended doses by their first birthday was mainly due to the first dose of pentavalent/DPT given before 42 days $(n=18(17.8 \%$ of missed doses $)$, mean (SD) age at vaccination $=37.9$ (6.1) days) (Supplemental Table 4) or the interval between pentavalent/DPT doses being less than 28 days $(n=32(31.7 \%)$, mean (SD) interval between doses $=24.2(5.2)$ days) or measles/MR vaccine given before 9 months of age $(n=32(31.7 \%)$, mean (SD) age at vaccination $=262.5(6.7)$ days) .

\section{Reasons for missed vaccination doses}

The most frequent reason for missed UIP doses reported by parents was a failure of health workers to record dates despite the child being vaccinated $(n=137 / 192$ reasons for missed doses, $71 \%$ ). Other important reasons included travel out of the village on the due date of vaccination ( $n=24,12.4 \%)$, misplaced vaccination cards $(n=20,10.4 \%)$ and a lack of awareness of the recommended schedule $(n=5,2.6 \%)$ (Supplemental Table 5).

\section{Factors associated with vaccination status and adherence to the UIP schedule}

Results of the univariate and multivariate analyses of factors associated with the vaccination status of children aged 12-23 months with a vaccination card at the time of survey are presented in Table 5. In the univariate analysis, children vaccinated in private facilities had a lower odds of full vaccination compared with those receiving vaccination in public facilities (POR: $0.40,95 \% \mathrm{Cl}=0.17-0.97$ ). Children whose parents agreed (strongly agreed or agreed) that they were familiar with the recommended UIP schedule were more likely to be fully vaccinated compared with those who did not agree (neutral, disagreed or strongly disagreed) to be familiar with the schedule (POR: $2.02,95 \% \mathrm{Cl}=$ 1.23 - 3.33). In addition, children whose parents had reported receiving information about the recommended UIP schedule during antenatal visits were more likely to be fully 
vaccinated than those who reportedly did not receive this information during the visits (POR: $2.53,95 \% \mathrm{Cl}=1.25-5.11)$.

In the multivariate analysis, self-reported familiarity with the UIP schedule (aPOR: 2.06, $95 \% \mathrm{Cl}=1.26-3.38)$, and receipt of information on recommended vaccinations during antenatal visits (aPOR: $2.16,95 \% \mathrm{Cl}=1.13-4.12$ ) were significantly associated with full vaccination status of children. Familiarity with the UIP schedule and receipt of information on recommended vaccinations during antenatal visits remained associated with full vaccination status in the supplementary analyses including all children regardless of source of vaccination history $(n=643)$ (Supplemental Table 6). However, children belonging to the other backward classes or the general category were more likely to be fully vaccinated compared with children from the scheduled castes in this analysis (aPOR: $6.02,95 \% \mathrm{Cl}=1.82-19.90)$. As sensitivity analysis, we also examined the factors associated with children's vaccination status after recategorizing the doses for which there were missing dates on vaccination cards and for which parents reported a failure in primary recording of the dates as "vaccinated". Familiarity with the UIP schedule and belonging to other backward classes or the general category (vs. scheduled castes) were associated with increased odds of full vaccination (Supplemental Table 7). The positive association between receiving information on the schedule during antenatal visits and full vaccination status remained, but was not statistically significant (aPOR: $2.05,95 \% \mathrm{Cl}=$ $0.78-5.43)$. The results of the multivariate analysis restricting the sample to children who were exclusively vaccinated at public health facilities $(n=570)$ were similar to the unrestricted sample (Supplemental Table 8). Birth order, social group, self-reported familiarity with and receipt of information on the UIP schedule during antenatal visits and receiving an incentive for completing the pentavalent/DPT series had a univariate association with the schedule-appropriate vaccination status of children at the $p \leq 0.20$ 
level (Table 6). In the multivariate analysis, children belonging to families of the other backward classes or the general category were more likely to be vaccinated according to schedule compared to those belonging to the scheduled castes (aPOR: $1.69,95 \% \mathrm{Cl}=$ $1.04-2.73)$. The findings of the multivariate analysis restricted to children receiving only public facility vaccination were similar to the model with all children included (Supplemental Table 9).

\section{Discussion}

The proportion of children aged 12-23 months who were fully vaccinated in rural Vellore was $96.4 \%$ and $84 \%$ using information from vaccination cards or parental recall and vaccination cards alone, respectively. The coverage estimate based on vaccination card information may be more reliable since the specificity of parental recall (to classify children's vaccination status) in our survey was low (21\%). The low specificity indicates that the use of parental recall possibly overestimates vaccination coverage, concurring with previous reports from India and elsewhere $[24,25]$. Full vaccination coverage in our survey however, differs considerably from the NFHS-4 estimates of $69.7 \%$ for children aged 12-23 months in rural Vellore and 74\% for the Vellore district overall, which are based on information from vaccination cards or parental recall[19]. One possible reason for the different estimates may be that immunization coverage was estimated for different birth cohorts in the NFHS-4 (2013-14) and our survey (2015-16). Since Vellore was selected as a high-focus district in 2015, the coverage of individual UIP antigens and fully vaccinated children may have increased between the two surveys. Another potential explanation from an independent audit of the NFHS-3 data is the significant difference in full vaccination coverage between children whose vaccination card was seen and those whose card was not seen during the survey [25]. The proportions of fully vaccinated children for these two categories was similar in our study (data not shown). 
Many ( 40\%) undervaccinated children had missed doses of BCG or Measles. The UIP recommends that BCG is administered at birth or as early as possible until one year of age [2]. Nearly $73 \%(n=25)$ of children with missed BCG doses were born in public facilities and since children may potentially have up to four immunization visits (at 6, 10, 14 weeks \& 9 -12 months) between birth and one year of age, the missed doses represent missed opportunities for routine immunization at birth or during later visits. If the opportunities to vaccinate these children were utilized, the coverage of BCG would have increased from $94.5 \%$ to $99.5 \%$. The first dose of measles is recommended during 9-12 months of age, children who are not vaccinated during the first year only have opportunity to catch up when returning for the booster doses of OPV and DPT at 16-24 months, when the second dose of measles is due [2]. Timely reminders to parents through health worker home visits or mobile-phone reminders may help improve uptake of measles vaccination during the first year of life $[26,27]$.

While many studies from India have reported socio-demographic disparities in vaccination coverage among young children, we found none in our study, suggesting a uniform delivery and uptake of routine immunization services in rural Vellore [28-33]. The observed disparity in full vaccination coverage by social group in the supplementary and sensitivity analyses may represent differences in parental beliefs and practices regarding childhood immunization or access to routine immunization services, which needs further investigation [28]. Of the non-socio-demographic factors assessed, parents' familiarity with the recommended UIP schedule and receiving information on the UIP schedule during antenatal visits were associated with increased odds of full vaccination. Nearly one-third of parents in our survey reported not being familiar with the UIP schedule for their children and a majority (> 80\%) had not heard of the recently introduced Measles-Rubella vaccine. With the recent addition of the rotavirus and pneumococcal conjugate vaccines to the UIP 
in some Indian states and planned nationwide introduction, health education interventions must aim to improve parental awareness of currently available and newly introduced UIP vaccines. The positive association between the reported receipt of information on the UIP schedule during antenatal visits and children's vaccination status highlights the importance of nudging parents towards vaccine uptake [21]. This finding is compatible with previous research from India which suggests that a higher number of antenatal visits (three or more) is associated with an increased likelihood of children completing the recommended immunization schedule [34]. Pregnant women are an important group for targeted educational intervention to sustain and improve uptake of routine childhood vaccination. We also analyzed children based on if they had received all the recommended vaccine doses during the first year of life according to the UIP schedule or not [31]. Many previous studies have reported the need to measure adherence to immunization schedules in addition to the traditionally used coverage metrics to evaluate the performance of routine immunization programs [35-38]. Despite the high proportion (84\%) of fully vaccinated children in our study, $13 \%$ of these children had one or more doses not given according to schedule (mainly due to less than optimal spacing of the multiple dose vaccines or early measles vaccination). Improper spacing of the pentavalent, DPT or OPV doses may lead to suboptimal immune response and according to current UIP guidelines, measles doses administered before 9 months of age are considered invalid and must be repeated [2,39]. These findings concur with various national, state and community-level evaluations which recommend the need for periodic assessment and improvement of age-appropriate immunization coverage among young children in India [31,33,40-42].

Our study had some limitations that should be considered when interpreting the findings: First, the exclusion of children without a vaccination card could have introduced a selection bias; however, we found no significant differences in the socio-demographic 
characteristics of children with and without vaccination cards (Supplemental Table 1). The results of the multivariate analysis were also similar whether restricted to children with a vaccination card or including all children irrespective of the source of vaccination history. Second, most parents (> 70\%) reported a failure of the health worker to record vaccination dates as the main reason for missed UIP doses and we were unable to verify these inconsistencies with provider-maintained records due to logistic constraints. It is possible that children received the doses for which the dates were not recorded and since the accuracy of coverage estimates largely depend on the quality of vaccination documentation, there is a need to improve primary data recording [43]. However, it is also likely that there was a degree of "social desirability" in parents' reasons for missed vaccinations for their children as the questionnaires were interviewer-administered [43]. In addition, some overlapping of the reasons for missed vaccination may have occurred; for example, the reported failure in primary data recording could have been due to misplaced cards during vaccination sessions. Third, we were unable to validate parents' knowledge of the vaccination schedule, which may have helped identify knowledge gaps to be addressed by government educational interventions. Fourth, it was also not possible to verify if the participating women had actually received information on the UIP schedule during antenatal visits. The observed association between receiving information on the schedule during antenatal visits with children's vaccination status may in part be due to a recall bias. We did not find any differences in reporting by place of delivery (public vs. private facility). Fifth, a degree of bias in the recording of study exposures may have occurred since the interviewers were not blinded to the children's vaccination records. However, information bias is expected to be minimal as the interviewers were unaware of the study outcomes during data collection. And lastly, as self-reported measures of 
household income are generally considered unreliable, we used the "type of dwelling" of eligible children as a relative measure of household wealth as previously reported $[29,44]$.

The limitations notwithstanding, this survey is the most recent independent assessment of routine immunization coverage among young children in Vellore, a Mission Indradhanush high-focus district. Our study was characterized by high vaccination card availability (> 94\%), improving the accuracy of the coverage estimates reported. In contrast, other independent household surveys from India have reported a vaccination card availability of $60-80 \%[30,31,45,46]$. We used standard EPI coverage survey methodology and recorded information using KoBo Toolbox, a free, open-source application for field data collection [20]. Mobile data collection is known to improve real-time supervision of data collectors, reduce the duration and cost of interviewing participants and decrease the possibility of data-entry errors at the point of collection $[47,48]$. In addition, the "5As taxonomy" aided identification of the possible role of "awareness" regarding the UIP schedule and "activation" through health education to pregnant women in the uptake of routine childhood vaccinations in rural Vellore and can be used for similar evaluations in other parts of India.

\section{Conclusions}

Periodic, region-specific evaluations of childhood immunization coverage are important to monitor progress and identify barriers to the achievement of national immunization program targets. We found higher coverage of the individual UIP antigens and full vaccination among children in rural Vellore than previously reported. Despite the high coverage, however, adherence to recommended schedule was not optimal. Self-reported familiarity with the UIP recommended schedule and receipt of information regarding childhood vaccinations during antenatal visits were associated with increased odds of full 
vaccination. Our study highlights the need to improve parental awareness of the currently available and newly introduced UIP vaccines. Health education interventions to improve coverage of routine vaccinations may benefit if targeted at pregnant women during antenatal visits.

\section{Acknowledgements}

The authors would like to thank all the parents who participated in the survey. We acknowledge the efforts of study personnel Mr. Annai Gunasekaran, Mr.Ethiraj, Mr.Arumugam, Mr.Viswanathan, Mr.Thirumani, Mr.Jeyapaul, Mr.Manivannan, Mr.Naveen kumar, Mr.Palani, Mr.Aravind and Mr.Surya for their hard work and technical support in the field. The authors also acknowledge Drs. Hanna Nohynek and Rajiv Sarkar for their assistance with designing the survey and helpful comments on an earlier version of this manuscript.

\section{Authors' contributions}

Study concept and design: MRF, JPN, GK, VB, VRM; Analysis and interpretation of data: MRF, JPN, GK, VRM; Drafting of the manuscript: MRF; Critical revision of the manuscript for important intellectual content: All authors; Statistical analysis: MRF; Obtained funding: JPN, GK; Study supervision: JPN, GK, VRM; Final approval: All authors

\section{Funding}

This fieldwork was supported by the Christian Medical College, Vellore, Tamil Nadu, India. MRF was supported by the Health Sciences Unit, Faculty of Social Sciences, Tampere University, Finland.

\section{Conflict of interest}

HL's research group has received funds from GSK and Merck to convene research symposium and holds a grant from GSK to support research on maternal vaccination. $\mathrm{HL}$ 
has served on the Merck Vaccines Strategic Advisory Board 2014-2016. None of the other

authors have conflicts of interest to declare.

\section{References}

[1] Government of India. Mission Indradhanush to Put Vaccination Efforts on High Speed 2015. http://pib.nic.in/newsite/mbErel.aspx?relid=117759 (accessed January 5, 2017).

[2] Ministry of Health and Family Welfare, Government of India. National Immunization Schedule for Infants, Children and Pregnant Women 2017.

[3] Paul S, Sahoo J. Four New Vaccines for Routine Immunization in India: What About Hemophilus Influenza B and Pneumococcal Vaccine? J Fam Med Prim Care 2015;4:9_ 12. doi:10.4103/2249-4863.152238.

[4] World Health Organization, WHO South-East Asia Region certified polio-free. SEARO n.d. http://www.searo.who.int/mediacentre/releases/2014/pr1569/en/ (accessed May 3, 2018).

[5] Black RE, Cousens S, Johnson HL, Lawn JE, Rudan I, Bassani DG, et al. Global, regional, and national causes of child mortality in 2008: a systematic analysis. The Lancet 2010;375:1969-87. doi:10.1016/S0140-6736(10)60549-1.

[6] International Institute for Population Sciences (IIPS). National Family Health Survey (NFHS - 4), 2015 - 2016: India 2016.

[7] Vashishtha VM, Kumar P. 50 years of immunization in India: progress and future. Indian Pediatr 2013;50:111-8.

[8] Travasso C. "Mission Indradhanush" targets India's unvaccinated children. BMJ 2015;350:h1688. doi:10.1136/bmj.h1688.

[9] Government of India. Monitoring one of the largest full immunization programmes of the world 2015. http://pib.nic.in/newsite/mbErel.aspx?relid=117967 (accessed November 8, 2016).

[10] Ministry of Health and Family Welfare, GOI. Impact of Mission Indradhanush 2017. http://pib.nic.in/newsite/PrintRelease.aspx?relid=160063 (accessed October 29, 2018).

[11] Rammohan A, Awofeso N. District-level variations in childhood immunizations in India: The role of socio-economic factors and health infrastructure. Soc Sci Med 1982 2015;145:163-72. doi:10.1016/j.socscimed.2015.05.004.

[12] Dasgupta R, Dasgupta P, Agrawal A. Decline in Immunization Coverage Across Wellperforming Districts in India: An Urban Conundrum? Indian J Pediatr 2014;81:847-9. doi:10.1007/s12098-014-1426-3.

[13] Balasubramanian P, Sundari Ravindran T. Pro-poor Maternity Benefit Schemes and Rural Women: Findings from Tamil Nadu. Economic and Political Weekly 2012; XLVII:19-22.

[14] Ministry of Health and Family Welfare, GOI. Conducting of Health Campaigns 2015. http://pib.nic.in/newsite/PrintRelease.aspx?relid=133711 (accessed October 29, 2018).

[15] Srinivasan R, Mohan VR, Venugopal S, Kang G. Utilization of Preventive and Curative Services in Five Rural Blocks in Vellore, India. Indian Pediatr 2017;54:777-8.

[16] Vashishtha VM, Choudhury P, Kalra A, Bose A, Thacker N, Yewale VN, et al. Indian Academy of Pediatrics (IAP) recommended immunization schedule for children aged 0 through 18 years--India, 2014 and updates on immunization. Indian Pediatr 2014;51:785-800. 
[17] World Health Organization. Training for mid-level managers. Module 7: The EPI coverage survey 2008.

[18] UX Apps. Random number generator - Apps on Google Play 2017. https://play.google.com/store/apps/details?id=ru.uxapps.random\&hl=en (accessed July 8, 2017).

[19] International Institute for Population Sciences (IIPS). National Family Health Survey-4 (2015-16) | District fact sheet, Vellore, Tamil Nadu 2017.

[20] KoBoToolbox | Data Collection Tools for Challenging Environments n.d. http://www.kobotoolbox.org/ (accessed April 4, 2018).

[21] Thomson A, Robinson K, Vallée-Tourangeau G. The 5As: A practical taxonomy for the determinants of vaccine uptake. Vaccine 2016;34:1018-24. doi:10.1016/j.vaccine.2015.11.065.

[22] Sun M, Ma R, Zeng Y, Luo F, Zhang J, Hou W. Immunization status and risk factors of migrant children in densely populated areas of Beijing, China. Vaccine 2010;28:126474. doi:10.1016/j.vaccine.2009.11.015.

[23] Gibson DG, Ochieng B, Kagucia EW, Obor D, Odhiambo F, O’Brien KL, et al. Individual level determinants for not receiving immunization, receiving immunization with delay, and being severely underimmunized among rural western Kenyan children. Vaccine 2015;33:6778-85. doi:10.1016/j.vaccine.2015.10.021.

[24] George K, Victor S, Abel R. Reliability of mother as an informant with regard to immunisation. Indian J Pediatr 1990;57:588-90.

[25] Binyaruka P, Borghi J. Validity of parental recalls to estimate vaccination coverage: evidence from Tanzania. BMC Health Serv Res 2018;18:440. doi:10.1186/s12913-0183270-z.

[26] Oyo-Ita A, Nwachukwu CE, Oringanje C, Meremikwu MM. Interventions for improving coverage of child immunization in low- and middle-income countries. In: The Cochrane Collaboration, editor. Cochrane Database Syst. Rev., Chichester, UK: John Wiley \& Sons, Ltd; 2011.

[27] Gibson DG, Ochieng B, Kagucia EW, Were J, Hayford K, Moulton LH, et al. Mobile phone-delivered reminders and incentives to improve childhood immunisation coverage and timeliness in Kenya (M-SIMU): a cluster randomised controlled trial. Lancet Glob Health 2017;5:e428-38. doi:10.1016/S2214-109X(17)30072-4.

[28] Shrivastwa N, Gillespie BW, Kolenic GE, Lepkowski JM, Boulton ML. Predictors of Vaccination in India for Children Aged 12-36 Months. Am J Prev Med 2015;49:S43544. doi:10.1016/j.amepre.2015.05.008.

[29] Francis MR, Nohynek H, Larson H, Balraj V, Mohan VR, Kang G, et al. Factors associated with routine childhood vaccine uptake and reasons for non-vaccination in India: 1998-2008. Vaccine 2018;36:6559-66. doi:10.1016/j.vaccine.2017.08.026.

[30] Devasenapathy N, Jerath SG, Sharma S, Allen E, Shankar AH, Zodpey S. Determinants of childhood immunisation coverage in urban poor settlements of Delhi, India: a cross-sectional study. BMJ Open 2016;6:e013015. doi:10.1136/bmjopen-2016013015.

[31] Murhekar MV, Kamaraj P, Kanagasabai K, Elavarasu G, Rajasekar TD, Boopathi K, et al. Coverage of childhood vaccination among children aged 12-23 months, Tamil Nadu, 2015, India. Indian J Med Res 2017;145:377-86. doi:10.4103/ijmr.IJMR_1666_15.

[32] Kumar A, Mohanty SK . Socio-economic differentials in childhood immunization in India, 1992-2006. J Popul Res 2011;28:301. doi:10.1007/s12546-011-9069-y. 
[33] Hoest C, Seidman JC, Lee G, Platts-Mills JA, Ali A, Olortegui MP, et al. Vaccine coverage and adherence to EPI schedules in eight resource poor settings in the MALED cohort study. Vaccine 2017;35:443-51. doi:10.1016/j.vaccine.2016.11.075.

[34] Dixit P, Dwivedi LK, Ram F. Strategies to Improve Child Immunization via Antenatal Care Visits in India: A Propensity Score Matching Analysis. PLoS ONE 2013;8:e66175. doi:10.1371/journal.pone.0066175.

[35] Clark A, Sanderson C. Timing of children's vaccinations in 45 low-income and middleincome countries: an analysis of survey data. Lancet Lond Engl 2009;373:1543-9. doi:10.1016/S0140-6736(09)60317-2.

[36] Hughes MM, Katz J, Englund JA, Khatry SK, Shrestha L, LeClerq SC, et al. Infant vaccination timing: Beyond traditional coverage metrics for maximizing impact of vaccine programs, an example from southern Nepal. Vaccine 2016;34:933-41. doi:10.1016/j.vaccine.2015.12.061.

[37] Dombkowski KJ, Lantz PM, Freed GL. The need for surveillance of delay in ageappropriate immunization. Am J Prev Med 2002;23:36-42.

[38] Fadnes LT, Nankabirwa V, Sommerfelt H, Tylleskär T, Tumwine JK, Engebretsen IMS, et al. Is vaccination coverage a good indicator of age-appropriate vaccination? A prospective study from Uganda. Vaccine 2011;29:3564-70. doi:10.1016/j.vaccine.2011.02.093.

[39] National Center for Immunization and Respiratory Diseases. General recommendations on immunization --- recommendations of the Advisory Committee on Immunization Practices (ACIP). MMWR Recomm Rep Morb Mortal Wkly Rep Recomm Rep 2011;60:1-64.

[40] Awofeso N, Rammohan A, Iqbal K. Age-appropriate vaccination against measles and DPT-3 in India - closing the gaps. BMC Public Health 2013;13:358. doi:10.1186/14712458-13-358.

[41] Yadav K, Srivastava R, Kumar R, Chinnakal P, Rai SK, Krishnan A. Significant vaccination delay can occur even in a community with very high vaccination coverage: evidence from Ballabgarh, India. J Trop Pediatr 2012;58:133-8. doi:10.1093/tropej/fmr059.

[42] Shrivastwa N, Gillespie BW, Lepkowski JM, Boulton ML. Vaccination Timeliness in Children Under India's Universal Immunization Program. Pediatr Infect Dis J 2016;35:955-60. doi:10.1097/INF.0000000000001223.

[43] Cutts FT, Claquin P, Danovaro-Holliday MC, Rhoda DA. Monitoring vaccination coverage: Defining the role of surveys. Vaccine 2016;34:4103-9. doi:10.1016/j.vaccine.2016.06.053.

[44] Morris SS, Carletto C, Hoddinott J, Christiaensen LJM. Validity of rapid estimates of household wealth and income for health surveys in rural Africa. J Epidemiol Community Health 2000;54:381-7. doi:10.1136/jech.54.5.381.

[45] Masthi NR, Krishna C. Coverage evaluation survey of the pentavalent vaccine using Global Positioning System technology and Google Earth in a rural area near Bangalore. Ann Trop Med Public Health 2017;10:76. doi:10.4103/1755-6783.205544.

[46] Varma GR, Kusuma YS. Immunization coverage in tribal and rural areas of Visakhapatnam district of Andhra Pradesh, India. J Public Health 2008;16:389-97. doi:10.1007/s10389-008-0186-9.

[47] Tomlinson M, Solomon W, Singh Y, Doherty T, Chopra M, ljumba P, et al. The use of mobile phones as a data collection tool: A report from a household survey in South Africa. BMC Med Inform Decis Mak 2009;9:51. doi:10.1186/1472-6947-9-51. 
[48] Medhanyie AA, Moser A, Spigt M, Yebyo H, Little A, Dinant G, et al. Mobile health data collection at primary health care in Ethiopia: a feasible challenge. J Clin Epidemiol 2015;68:80-6. doi:10.1016/j.jclinepi.2014.09.006.

[49] Keja K, Chan C, Hayden G, Henderson RH. Expanded programme on immunization. World Health Stat Q Rapp Trimest Stat Sanit Mond 1988;41:59-63.

\section{Tables}

Table 1: Definitions of vaccination status and schedule-appropriate vaccination status of children aged 12-23 months in rural Vellore, southern India

Outcome Definition

Primary:

Vaccination status [49]

Secondary:

Schedule-appropriate vaccination status [31]
Fully vaccinated: Children who received one dose of BCG, three doses of pentavalent (containing antigens against diphtheria, pertussis, tetanus, hepatitis B and Haemophilus influenzae B) or DPT, three doses of OPV (excluding the zero dose) and one dose of measles containing vaccine (monovalent measles or Measles-Rubella), irrespective of age at receipt of individual doses; Undervaccinated: Children who missed one or more recommended doses or those who received none of the recommended doses

Schedule-appropriate: Children who were vaccinated at the right age and interval as per the UIP schedule, i.e. those who received (1) BCG at birth or as early as possible until one year of age, (2) pentavalent/DPT \& OPV vaccines - first dose 6 weeks after birth and subsequent doses with at least four week (28 day) intervals and receipt of all three doses before the first birthday (3) Measles containing vaccine (monovalent measles or Measles-Rubella) administered after completion of 9 months of age, but before their first birthday; Not schedule-appropriate: Children who either missed one or more recommended doses or did not receive one or more doses at the recommended age and interval as per the UIP schedule during the first year of life (according to the definition above)

Table 2: Socio-demographic characteristics of children aged 12-23 months and their parents in rural Vellore, southern India $(\mathrm{N}=643)$

\begin{tabular}{lccc} 
Characteristic & Category & Frequency & Percentage (\%) \\
\hline Child characteristics & & & \\
Child's age (months) & $12-17$ & 308 & 47.9 \\
Child's gender & $18-23$ & 335 & 52.1 \\
& Female & 305 & 47.4
\end{tabular}




\begin{tabular}{lccc} 
& Male & 338 & 52.6 \\
Child's birth order & 1 & 275 & 42.8 \\
& 2 & 279 & 43.4 \\
\multirow{3}{*}{ Place of birth } & $\geq 3$ & 89 & 13.8 \\
& Public facility & 518 & 80.6 \\
Place of vaccination & Private facility & 119 & 18.5 \\
& Home/Others & 6 & 0.9 \\
& Public facility & 605 & 94.2 \\
\hline
\end{tabular}

\section{Parental characteristics}

\begin{tabular}{|c|c|c|c|}
\hline \multirow{3}{*}{ Respondent } & Mother & 611 & 95.0 \\
\hline & Father & 17 & 2.6 \\
\hline & Others & 15 & 2.4 \\
\hline \multirow{4}{*}{$\begin{array}{l}\text { Age of mother at birth of } \\
\text { child (years) }\end{array}$} & $<20$ & 74 & 11.5 \\
\hline & $20-30$ & 526 & 81.8 \\
\hline & $>30$ & 43 & 6.7 \\
\hline & Single & 3 & 0.5 \\
\hline \multirow{3}{*}{$\begin{array}{l}\text { Marital status of } \\
\text { respondent }\end{array}$} & Married & 627 & 97.5 \\
\hline & Divorced/Widowed & 13 & 2.0 \\
\hline & Illiterate & 17 & 2.6 \\
\hline \multirow[t]{3}{*}{ Mother's education } & Up to 12th standard & 527 & 82.0 \\
\hline & Diploma/Degree & 99 & 15.4 \\
\hline & Illiterate & 31 & 4.8 \\
\hline \multirow[t]{3}{*}{ Father's education } & Up to 12 th standard & 522 & 81.2 \\
\hline & Diploma/Degree & 90 & 14.0 \\
\hline & Homemaker & 561 & 87.2 \\
\hline \multirow[t]{3}{*}{ Mothers occupation } & Wage earner & 68 & 10.5 \\
\hline & Salary earner/business & 14 & 2.2 \\
\hline & Unemployed & 16 & 2.5 \\
\hline \multirow{2}{*}{$\begin{array}{l}\text { Fathers occupation }(n= \\
638)\end{array}$} & Wage earner & 457 & 71.6 \\
\hline & Salary earner/business & 165 & 25.9 \\
\hline \multicolumn{4}{|l|}{$\frac{\text { Household }}{\text { characteristics }}$} \\
\hline \multirow{3}{*}{ Religion } & Hindu & 623 & 96.9 \\
\hline & Others & 20 & 3.1 \\
\hline & $<5$ & 217 & 33.7 \\
\hline \multirow[t]{3}{*}{ Household size } & $5-10$ & 418 & 65.0 \\
\hline & $>10$ & 8 & 1.3 \\
\hline & Mud & 19 & 2.9 \\
\hline \multirow[t]{2}{*}{ Type of dwelling } & Semi-cemented & 32 & 5.0 \\
\hline & Cemented & 592 & 92.1 \\
\hline Social group & $\mathrm{SC}^{*}$ & 164 & 25.5 \\
\hline
\end{tabular}




\begin{tabular}{cccc} 
& ST & 68 & 10.6 \\
& OBC/general & 411 & 63.9 \\
\multirow{2}{*}{ Ration card ownership } & Yes & 595 & 92.5 \\
& No & 48 & 7.5 \\
\hline
\end{tabular}

*SC: Scheduled castes, ST: Scheduled tribes, OBC: Other Backward classes (for more detail see supplemental material)

Table 3: Non-socio-demographic characteristics of survey participants in rural Vellore, southern India $(\mathrm{N}=643)$

\begin{tabular}{|c|c|c|c|}
\hline Characteristic & Categories & Frequency & Percentage (\%) \\
\hline \multicolumn{4}{|l|}{ Access } \\
\hline $\begin{array}{l}\text { Travel to immunization } \\
\text { facility (proxy for distance } \\
\text { to facility) }\end{array}$ & Private/Public transport & 420 & 65.3 \\
\hline \multirow{6}{*}{$\begin{array}{l}\text { Awareness } \\
\text { Heard about recently } \\
\text { introduced Measles- } \\
\text { Rubella vaccine } \\
\text { I think immunization is } \\
\text { important to keep my child } \\
\text { healthy } \\
\text { I am familiar with the } \\
\text { immunization schedule } \\
\text { (individual vaccines \& } \\
\text { timing of doses) }\end{array}$} & No & 523 & 81.3 \\
\hline & Yes & 120 & 18.7 \\
\hline & Don't agree $\left(\mathrm{N}^{\star}\right)$ & 4 & 0.7 \\
\hline & Agree $(S A, A)$ & 639 & 99.3 \\
\hline & $\begin{array}{c}\text { Don't agree (N,DA, } \\
\text { SDA) }\end{array}$ & 180 & 28.0 \\
\hline & Agree $(S A, A)$ & 463 & 72.0 \\
\hline \multicolumn{4}{|l|}{ Affordability } \\
\hline $\begin{array}{l}\text { The timing of immunization } \\
\text { sessions was convenient } \\
\text { for me }\end{array}$ & $\begin{array}{c}\text { Don't agree }(\mathrm{N}, \mathrm{DA}) \\
\text { Agree }(\mathrm{SA}, \mathrm{A})\end{array}$ & $\begin{array}{c}45 \\
598\end{array}$ & $\begin{array}{c}7.0 \\
93.0\end{array}$ \\
\hline \multicolumn{4}{|l|}{ Acceptance } \\
\hline \multirow{2}{*}{$\begin{array}{l}\text { Self-reported hesitancy } \\
\text { with one or more } \\
\text { childhood vaccines }\end{array}$} & Hesitant $\left(\mathrm{N}, \mathrm{SH}, \mathrm{VH}^{* \star}\right)$ & 365 & 56.8 \\
\hline & Not hesitant $(\mathrm{NH}, \mathrm{NTH})$ & 278 & 43.2 \\
\hline \multirow{2}{*}{$\begin{array}{l}\text { I trust the information } \\
\text { provided by the health } \\
\text { workers on immunizations } \\
\text { Activation }\end{array}$} & Don't agree $(\mathrm{N})$ & 12 & 1.9 \\
\hline & Agree $(S A, A)$ & 631 & 98.1 \\
\hline \multirow{2}{*}{ Health worker home visits } & No/Not sure & 139 & 21.6 \\
\hline & Yes & 504 & 78.4 \\
\hline \multirow{2}{*}{$\begin{array}{l}\text { Information about } \\
\text { recommended vaccines } \\
\text { provided during antenatal } \\
\text { visits }\end{array}$} & No/Not sure & 65 & 10.1 \\
\hline & Yes & 578 & 89.9 \\
\hline
\end{tabular}


Received incentive for

completing

No

208

pentavalent/DPT series ( $\mathrm{n}$

Yes

433

67.6

*SA: Strongly agree, A: Agree, N: Neutral, DA: Disagree, SDA: Strongly disagree

** SH: Strongly hesitant, VH: Very hesitant, N: Neutral, NH: Not hesitant, NTH: Not too hesitant 
Table 4: Coverage and vaccination status of children aged 12-23 months in rural Vellore, southern India

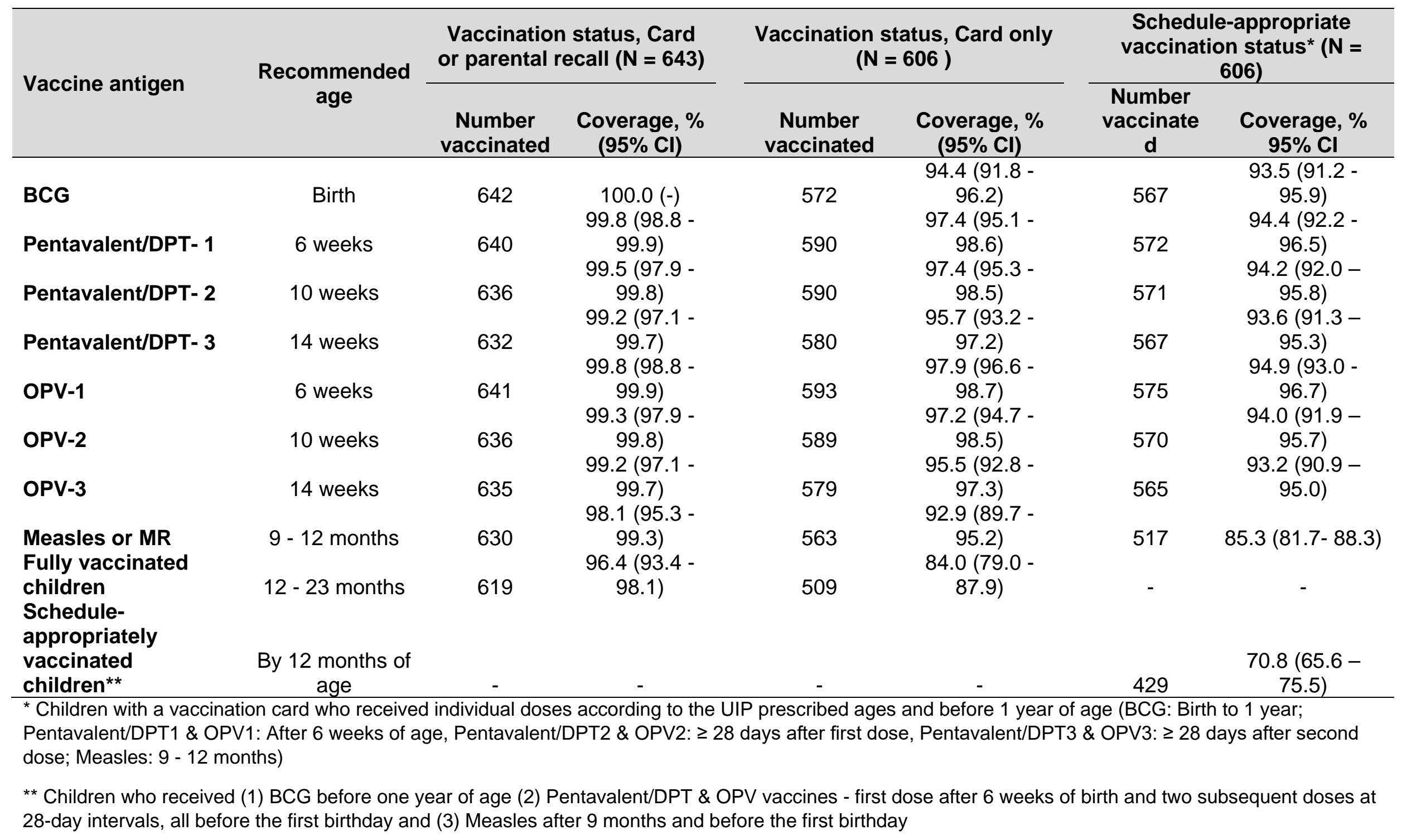


Table 5: Participant characteristics and their association with vaccination status of children aged 12-23 months in rural Vellore, southern India $(\mathrm{N}=606)$

\begin{tabular}{|c|c|c|c|c|c|}
\hline \multirow[b]{2}{*}{ Characteristic } & \multirow[b]{2}{*}{ Categories } & \multicolumn{2}{|c|}{ Proportions, n (\%) } & \multicolumn{2}{|c|}{ Prevalence Odds Ratio (95\% Cl) } \\
\hline & & $\begin{array}{c}\text { Fully } \\
\text { vaccinated }\end{array}$ & Undervaccinated & Unadjusted & Adjusted \\
\hline \multicolumn{6}{|l|}{ Socio-demographic } \\
\hline \multirow{2}{*}{$\begin{array}{l}\text { Child's age (months) } \\
\text { (mont }\end{array}$} & $12-17$ & $236(46.4)$ & $56(57.7)$ & Ref & Ref \\
\hline & $18-23$ & $273(53.6)$ & $41(42.3)$ & $1.58(0.94-2.65)^{\star}$ & $1.64(0.99-2.70)^{*}$ \\
\hline \multirow{3}{*}{ Child's gender } & Male & 257 (50.5) & 62 (63.9) & Ref & Ref \\
\hline & Female & $252(49.5)$ & $35(36.1)$ & $1.74(0.97-3.01)^{\star}$ & $1.70(0.92-3.11)^{\star}$ \\
\hline & 1 & $210(41.3)$ & $49(50.5)$ & Ref & Ref \\
\hline \multirow[t]{2}{*}{ Child's birth order } & 2 & $230(45.2)$ & $37(38.1)$ & $1.45(1.01-1.95)^{\star \star}$ & $1.24(0.86-1.79)$ \\
\hline & $\geq 3$ & $69(13.6)$ & $11(11.3)$ & $1.46(0.70-3.09)$ & $1.77(0.77-4.10)$ \\
\hline \multirow{2}{*}{ Place of vaccination } & Public facility & $484(95.1)$ & $86(88.7)$ & Ref & Ref \\
\hline & Private facility & $25(4.9)$ & $11(11.3)$ & $0.40(0.17-0.97)^{\star \star}$ & $0.62(0.20-1.92)$ \\
\hline \multirow{4}{*}{$\begin{array}{l}\text { Mother's age at birth } \\
\text { of child (years) }\end{array}$} & $<20$ & $60(11.8)$ & $9(9.3)$ & Ref & - \\
\hline & $20-30$ & $417(81.9)$ & 81 (83.5) & $0.77(0.34-1.73)$ & - \\
\hline & $>30$ & 32 (6.3) & $7(7.2)$ & $0.69(0.20-2.39)$ & - \\
\hline & Illiterate & $11(2.2)$ & $5(5.2)$ & Ref & - \\
\hline \multirow[t]{3}{*}{ Mother's education } & Upto 12th standard & $424(83.3)$ & 73 (75.3) & $2.64(0.54-13.02)$ & - \\
\hline & Diploma/Degree & $74(14.5)$ & 19 (19.5) & $1.77(0.34-9.09)$ & - \\
\hline & Illiterate & $23(4.5)$ & $4(4.1)$ & Ref & - \\
\hline \multirow[t]{3}{*}{ Father's education } & Upto 12th standard & 417 (81.9) & $76(78.4)$ & $0.95(0.16-5.52)$ & - \\
\hline & Diploma/Degree & $69(13.6)$ & $17(17.5)$ & $0.71(0.11-4.56)$ & - \\
\hline & Homemaker & $448(88.0)$ & 80 (82.5) & Ref & - \\
\hline \multirow[t]{3}{*}{ Mother's occupation } & Wage earner & $51(10.0)$ & $14(14.4)$ & $0.65(0.32-1.31)$ & - \\
\hline & Salary earner/business & $10(2.0)$ & $3(3.1)$ & $0.60(0.17-2.06)$ & - \\
\hline & Unemployed & $12(2.4)$ & $4(4.1)$ & Ref & Ref \\
\hline \multirow{2}{*}{$\begin{array}{l}\text { Father's } \\
\text { occupation*** }\end{array}$} & Wage earner & $365(72.4)$ & $63(65.0)$ & $1.93(0.73-5.13)^{\star}$ & $1.51(0.61-3.79)$ \\
\hline & Salary earner/business & $127(25.2)$ & $30(30.9)$ & $1.41(0.43-4.64)$ & $1.22(0.42-3.60)$ \\
\hline \multirow{2}{*}{ Religion } & Hindu & $495(97.3)$ & 94 (96.9) & Ref & - \\
\hline & Others & $14(2.7)$ & $3(3.1)$ & $0.89(0.16-4.81)$ & - \\
\hline \multirow{2}{*}{ Household size } & $<5$ & $171(33.6)$ & $34(35.1)$ & Ref & - \\
\hline & $5-10$ & $331(65.0)$ & $62(63.9)$ & $1.06(0.71-1.58)$ & - \\
\hline
\end{tabular}




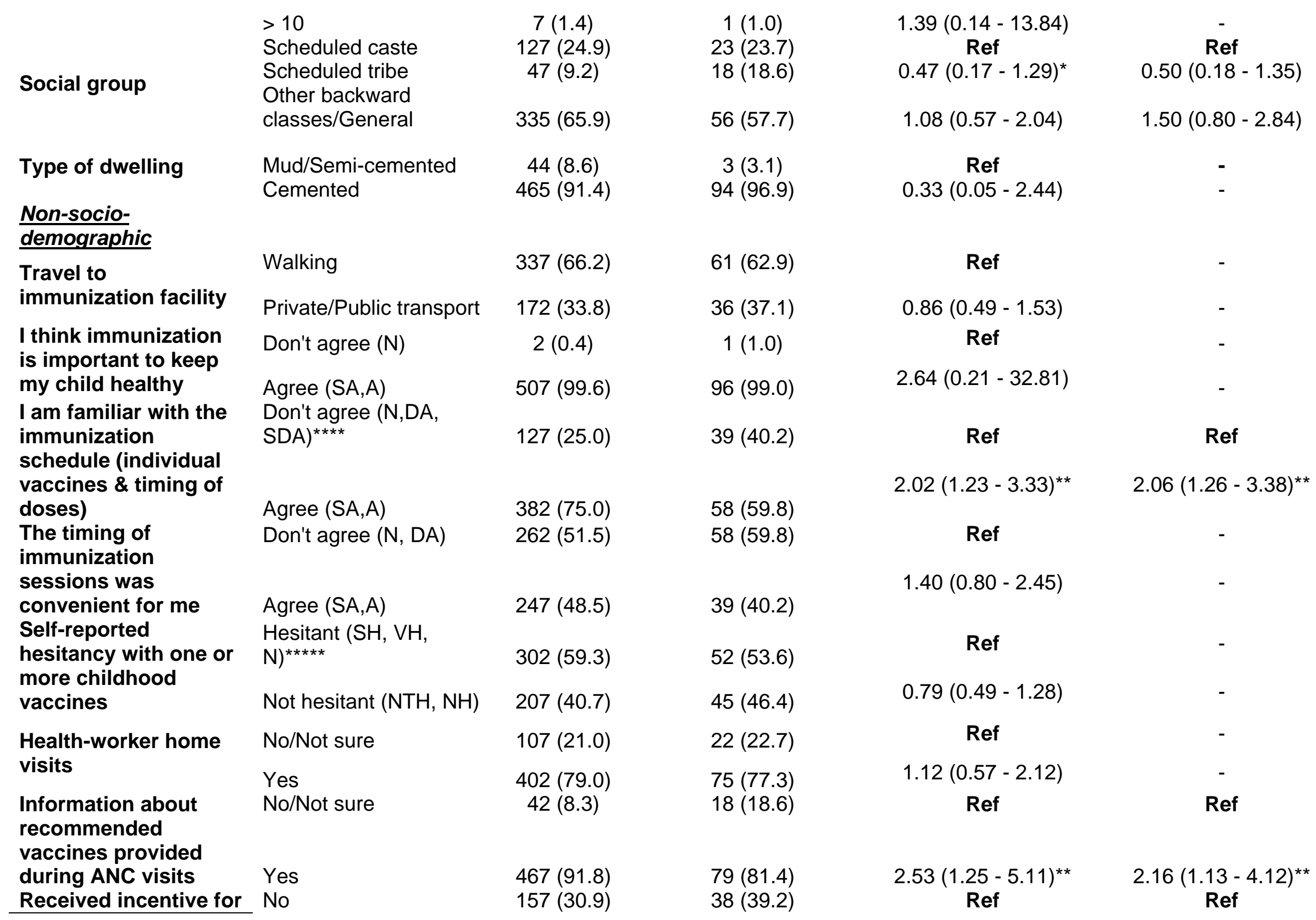




\section{completing}

pentavalent/DPT

series

Yes

351 (69.1)

59 (60.8)

1.44 (0.91 - 2.29)

$1.48(0.83-2.58)$

${ }^{*} \mathrm{p}<0.10 ;{ }^{* \star} \mathrm{p}<0.05,{ }^{* \star \star} \mathrm{n}=5$ missing observations for father's occupation, $\mathrm{N}=601$ for multivariate model, ${ }^{\star \star \star \star}$ SA: Strongly agree, A: Agree, N: Neutral, DA:

Disagree, SDA: Strongly disagree, ${ }^{\star \star \star \star *} \mathrm{SH}$ : Strongly Hesitant, VH: Very hesitant, N: Neutral, NTH: Not too hesitant, NH: Not hesitant

Table 6: Participant characteristics and their association with schedule-appropriate vaccination status of children aged 12-23

months in rural Vellore, southern India $(N=606)$

\begin{tabular}{|c|c|c|c|c|c|}
\hline \multirow{2}{*}{ Characteristic } & \multirow{2}{*}{ Categories } & \multicolumn{2}{|c|}{ Proportions, n (\%) } & \multicolumn{2}{|c|}{ Prevalence Odds Ratio $(95 \% \mathrm{Cl})$} \\
\hline & & $\begin{array}{l}\text { Schedule- } \\
\text { appropriate }\end{array}$ & $\begin{array}{l}\text { Not schedule- } \\
\text { appropriate }\end{array}$ & Unadjusted & Adjusted \\
\hline \multicolumn{6}{|l|}{ Socio-demographic } \\
\hline \multirow{2}{*}{ Child's age (months) } & $12-17$ & $206(48.0)$ & $86(48.6)$ & Ref & - \\
\hline & $18-23$ & $223(52.0)$ & $91(51.4)$ & $1.02(0.74-1.43)$ & - \\
\hline \multirow{2}{*}{ Child's gender } & Male & $217(50.6)$ & $102(57.6)$ & Ref & - \\
\hline & Female & $212(49.4)$ & $75(42.4)$ & $1.32(0.83-2.14)$ & - \\
\hline \multirow{3}{*}{ Child's birth order } & 1 & $174(40.6)$ & $85(48.0)$ & Ref & Ref \\
\hline & 2 & $198(46.2)$ & $69(39.0)$ & $1.40(1.04-1.88)^{\star \star}$ & $1.36(0.98-1.88)$ \\
\hline & $\geq 3$ & $57(13.2)$ & $23(13.0)$ & $1.21(0.75-1.95)$ & $1.64(0.84-3.19)$ \\
\hline \multirow{2}{*}{ Place of vaccination } & Public facility & 407 (94.9) & $163(92.1)$ & Ref & - \\
\hline & Private facility & $22(5.1)$ & $14(7.9)$ & $0.62(0.30-1.30)$ & - \\
\hline \multirow{4}{*}{$\begin{array}{l}\text { Mother's age at birth } \\
\text { of child (years) }\end{array}$} & $<20$ & $46(10.7)$ & $23(13.0)$ & Ref & - \\
\hline & $20-30$ & $354(82.5)$ & $144(81.4)$ & $1.22(0.69-2.19)$ & - \\
\hline & $>30$ & $29(6.8)$ & $10(5.6)$ & $1.45(0.58-3.64)$ & - \\
\hline & Illiterate & $10(2.3)$ & $6(3.4)$ & Ref & - \\
\hline \multirow[t]{3}{*}{ Mother's education } & Upto 12th standard & 357 (83.2) & $140(79.1)$ & $1.53(0.36-6.58)$ & - \\
\hline & Diploma/Degree & $62(14.5)$ & $31(17.5)$ & $1.20(0.29-4.99)$ & - \\
\hline & Illiterate & $19(4.4)$ & $8(4.5)$ & Ref & - \\
\hline \multirow{2}{*}{ Father's education ${ }^{\star \star \star}$} & Upto 12th standard & $353(82.3)$ & $140(79.1)$ & $1.06(0.37-3.08)$ & - \\
\hline & Diploma/Degree & $57(13.3)$ & $29(16.4)$ & $0.83(0.27-2.49)$ & - \\
\hline
\end{tabular}




\begin{tabular}{|c|c|c|c|c|c|}
\hline \multirow{3}{*}{ Mother's occupation } & Homemaker & $378(88.1)$ & $150(84.8)$ & Ref & - \\
\hline & Wage earner & $42(9.8)$ & $23(13.0)$ & $0.72(0.33-1.49)$ & - \\
\hline & $\begin{array}{l}\text { Salary } \\
\text { earner/business }\end{array}$ & $9(2.1)$ & $4(2.2)$ & $0.89(0.28-2.82)$ & - \\
\hline \multirow{3}{*}{ Father's occupation } & Unemployed & $10(2.4)$ & $6(3.4)$ & Ref & - \\
\hline & Wage earner & $311(73.3)$ & $117(66.1)$ & $1.59(0.58-4.38)$ & - \\
\hline & $\begin{array}{l}\text { Salary } \\
\text { earner/business }\end{array}$ & $103(24.3)$ & $54(30.5)$ & $1.14(0.39-3.33)$ & - \\
\hline \multirow{3}{*}{ Religion } & Hindu & $419(97.7)$ & $170(96.0)$ & Ref & - \\
\hline & Others & $10(2.3)$ & $7(4.0)$ & $0.58(0.17-1.92)$ & - \\
\hline & $<5$ & $147(34.3)$ & $58(32.8)$ & Ref & - \\
\hline \multirow[t]{2}{*}{ Household size } & $5-10$ & $276(64.3)$ & $117(66.1)$ & $0.93(0.65-1.33)$ & - \\
\hline & $>10$ & $6(1.4)$ & $2(1.1)$ & $1.18(0.21-6.62)$ & - \\
\hline \multirow{3}{*}{ Social group } & Scheduled caste & $101(23.5)$ & $49(27.7)$ & Ref & Ref \\
\hline & Scheduled tribe & 39 (9.1) & $26(14.7)$ & $0.73(0.34-1.54)$ & $0.73(0.34-1.57)$ \\
\hline & $\begin{array}{l}\text { Other backward } \\
\text { classes/General } \\
\text { Mud/Semi- }\end{array}$ & $289(67.4)$ & $102(57.6)$ & $1.37(0.84-2.24)$ & $1.69(1.04-2.73)^{\star \star}$ \\
\hline Type of dwelling & cemented & $36(8.4)$ & $11(6.2)$ & Ref & - \\
\hline \multicolumn{6}{|l|}{$\frac{\text { Non-socio- }}{\text { demographic }}$} \\
\hline \multirow{2}{*}{$\begin{array}{l}\text { Travel to } \\
\text { immunization facility }\end{array}$} & Walking & $285(66.4)$ & $113(63.8)$ & Ref & - \\
\hline & $\begin{array}{l}\text { Private/Public } \\
\text { transport }\end{array}$ & $144(33.6)$ & $64(36.2)$ & $0.89(0.55-1.44)$ & - \\
\hline \multirow{2}{*}{$\begin{array}{l}\text { I think immunization } \\
\text { is important to keep } \\
\text { my child healthy }\end{array}$} & Don't agree $(\mathrm{N})$ & $2(0.5)$ & $1(0.6)$ & Ref & - \\
\hline & Agree $(S A, A)^{\star \star \star \star}$ & $427(99.5)$ & $176(99.2)$ & $1.21(0.1-15.1)$ & - \\
\hline \multirow{2}{*}{$\begin{array}{l}\text { I am familiar with the } \\
\text { immunization } \\
\text { schedule (individual } \\
\text { vaccines \& timing of } \\
\text { doses) }\end{array}$} & $\begin{array}{l}\text { Don't agree (N,DA, } \\
\text { SDA) }\end{array}$ & $108(25.2)$ & $58(32.8)$ & Ref & Ref \\
\hline & Agree $(S A, A)$ & $321(74.8)$ & $119(67.2)$ & $1.44(0.91-2.30)$ & $1.42(0.90-2.22)$ \\
\hline
\end{tabular}




\begin{tabular}{|c|c|c|c|c|c|}
\hline \multirow{2}{*}{$\begin{array}{l}\text { The timing of } \\
\text { immunization } \\
\text { sessions was } \\
\text { convenient for me }\end{array}$} & Don't agree $(\mathrm{N}, \mathrm{DA})$ & $31(7.2)$ & $12(6.8)$ & Ref & - \\
\hline & Agree (SA,A) & 398 (92.8) & $165(93.2)$ & $0.93(0.44-1.99)$ & - \\
\hline \multirow{2}{*}{$\begin{array}{l}\text { Self-reported } \\
\text { hesitancy with one or } \\
\text { more childhood } \\
\text { vaccines }\end{array}$} & $\begin{array}{l}\text { Hesitant (SH, VH, } \\
\mathrm{N})^{\star \star \star \star \star}\end{array}$ & $259(60.4)$ & $95(53.7)$ & Ref & - \\
\hline & $\begin{array}{l}\text { Not hesitant (NTH, } \\
\text { NH) }\end{array}$ & $170(39.6)$ & $82(46.3)$ & $0.76(0.54-1.07)$ & - \\
\hline \multirow{2}{*}{$\begin{array}{l}\text { Health-worker home } \\
\text { visits }\end{array}$} & No/Not sure & $88(20.5)$ & $41(23.2)$ & Ref & - \\
\hline & Yes & 341 (79.5) & $136(76.8)$ & $1.16(0.68-2.00)$ & - \\
\hline $\begin{array}{l}\text { Information about } \\
\text { recommended } \\
\text { vaccines provided }\end{array}$ & No/Not sure & $36(8.4)$ & $24(13.6)$ & Ref & Ref \\
\hline during ANC visits & Yes & $393(91.6)$ & $153(86.4)$ & $1.71(0.97-3.01)^{\star}$ & $1.42(0.90-2.22)$ \\
\hline \multirow{2}{*}{$\begin{array}{l}\text { Received incentive } \\
\text { for completing } \\
\text { pentavalent/DPT } \\
\text { series }\end{array}$} & No & $130(30.3)$ & 65 (36.9) & Ref & Ref \\
\hline & Yes & $299(69.7)$ & $111(63.1)$ & $1.35(0.98-1.86)^{\star}$ & $1.55(0.82-2.94)$ \\
\hline
\end{tabular}

$=605$ for multivariate model, ${ }^{\star \star \star \star}$ SA: Strongly agree, A: Agree, N: Neutral,

DA: Disagree, SDA: Strongly disagree, ${ }^{\star \star \star \star \star ~ S H: ~ S t r o n g l y ~ H e s i t a n t, ~ V H: ~ V e r y ~ h e s i t a n t, ~ N: ~ N e u t r a l, ~ N T H: ~ N o t ~ t o o ~ h e s i t a n t, ~ N H: ~ N o t ~ h e s i t a n t ~}$ 